\title{
MYOSITIS OSSIFICANS CIRCUMSCRIPTA
}

\author{
Report of Four Cases Without History of Injury
}

\author{
Dennis C. Paterson, Adelaide, Australia
}

From the Department of Orthopaedic Surgery, Adelaide Children's Hospital

Ackerman (1958) described myositis ossificans as an "extra-osseous, localised, nonneoplastic formation of bone and cartilage". This is somewhat inaccurate because often the lesion may not even contain or be connected with bone. Moreover, the term "myositis" is unsatisfactory as there is no good evidence of inflammation.

Many classifications of this condition have been suggested. That of Noble (1924), which includes three types, is the most lucid: 1) Myositis ossificans progressiva. This is a metabolic disorder occurring in children with widespread metamorphosis of muscle into bone, all of the skeletal muscles becoming involved progressively. It is ultimately fatal. 2) Traumatic myositis ossificans circumscripta. This follows local trauma which may be either acute (a single injury), or chronic (repeated slight injuries or an occupational injury, such as strain of the adductor longus tendon in jockeys). 3) Myositis ossificans circumscripta without history of trauma. This is usually found in paraplegia, chronic infections, burns and poliomyelitis, but may occur

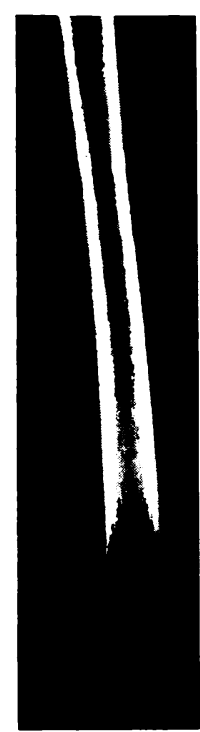

FIG. 1

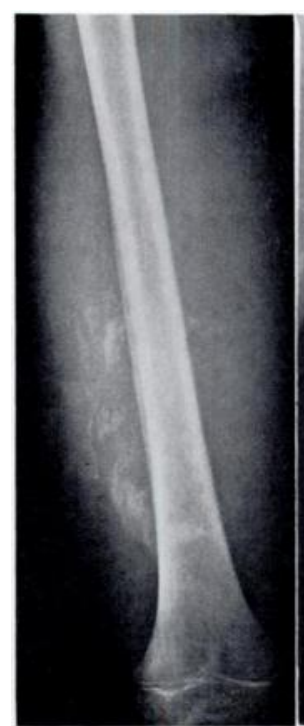

FIG. 2

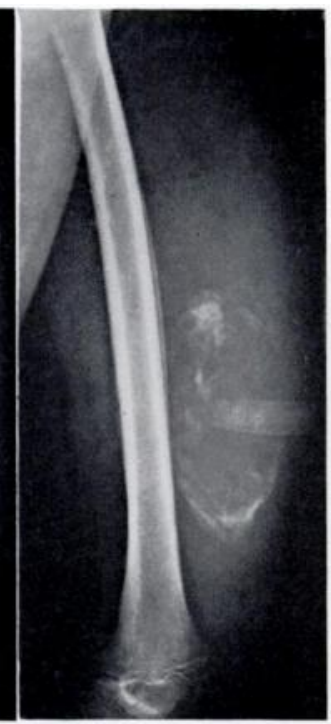

FIG. 3

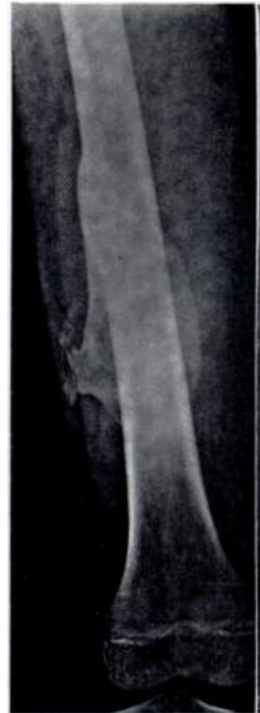

FiG. 4

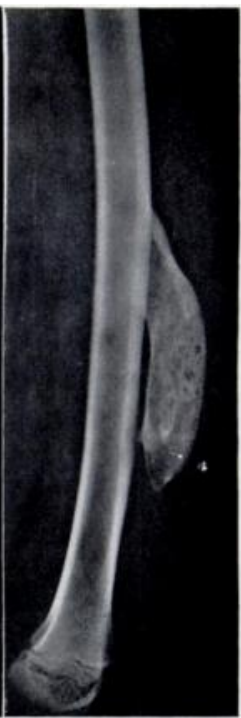

FIG. 5

Case 1. Figure 1-Antero-posterior radiograph at the onset of symptoms showing periosteal new bone formation. Figure 2-Antero-posterior radiograph eleven days later, showing a large calcified mass. Figure 3-Lateral view of the mass. Figure 4-Antero-posterior radiograph of the thigh four years later. Figure 5-Lateral view at four years.

independently of these conditions. Jeffreys and Stiles (1966) suggested that the condition be referred to as "pseudomalignant osseous tumour of soft tissue", but I submit that this term should be avoided. It is more important to have a clear understanding of the clinical and histopathological picture so that incorrect diagnoses can be avoided than to introduce such new terms.

Seventy-five per cent of cases of myositis ossificans are associated with trauma, most commonly affecting the anterior and lateral aspects of the thigh and the upper arm. The purpose of this article is to present four cases unassociated with any known direct trauma, in three of which the diagnosis caused considerable anxiety. 


\section{CASE REPORTS}

Case 1-A boy aged seven presented with a swelling of the thigh of three weeks' duration, with rapid loss of weight but without any history of injury. He had a marked, painful limp and the swelling, though initially painless, was by then very painful. He looked toxic with a temperature of 37.8 degrees Centigrade. There was a diffuse swelling involving the whole of the thigh. The mass was tender, firm, and warm to the touch: there was no redness of the overlying skin.

He was anaemic. The white blood count was 13,800 with 78 per cent neutrophils. The blood sedimentation rate was 30 millimetres in the first hour. All other blood tests were normal. Radiographs showed periosteal new bone formation along the shaft of the femur (Fig. 1).

At first, osteomyelitis of the femur was suspected and treatment with erythromycin was begun. But when the pyrexia continued and the mass was found to be becoming harder and larger, the possibility of osteosarcoma was considered and surgical exploration was decided upon. At operation an irregular, firm mass of cartilaginous mucoid material was found and a piece was removed for biopsy. After operation the thigh became larger and hot, with engorged superficial veins, though the tenderness became progressively less (Fig. 6).

Histology-Microscopic examination showed young,

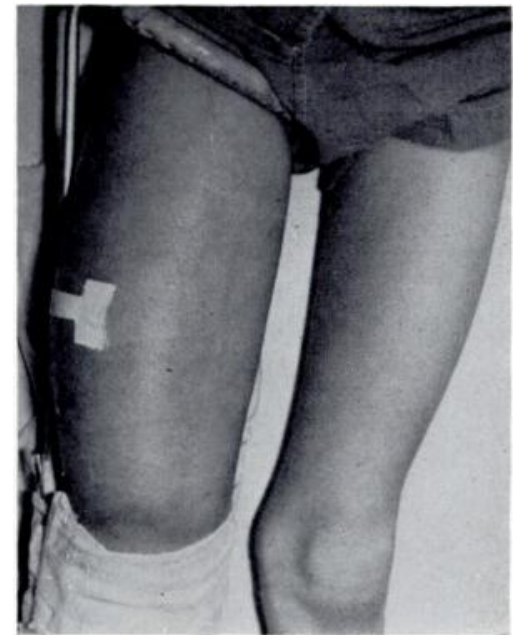

FIG. 6

Case 1-The right thigh after biopsy showing swelling of the whole thigh and engorgement of the superficial veins. rapidly proliferating, fibroblastic tissue and the remains of muscle fibres, indicating that these changes had occurred in muscle (Fig. 7). Mitotic figures were present. The cells were both stellate and spindle-shaped-the two extremes of cell differentiation (Fig. 8). The changes became more advanced with differentiation of

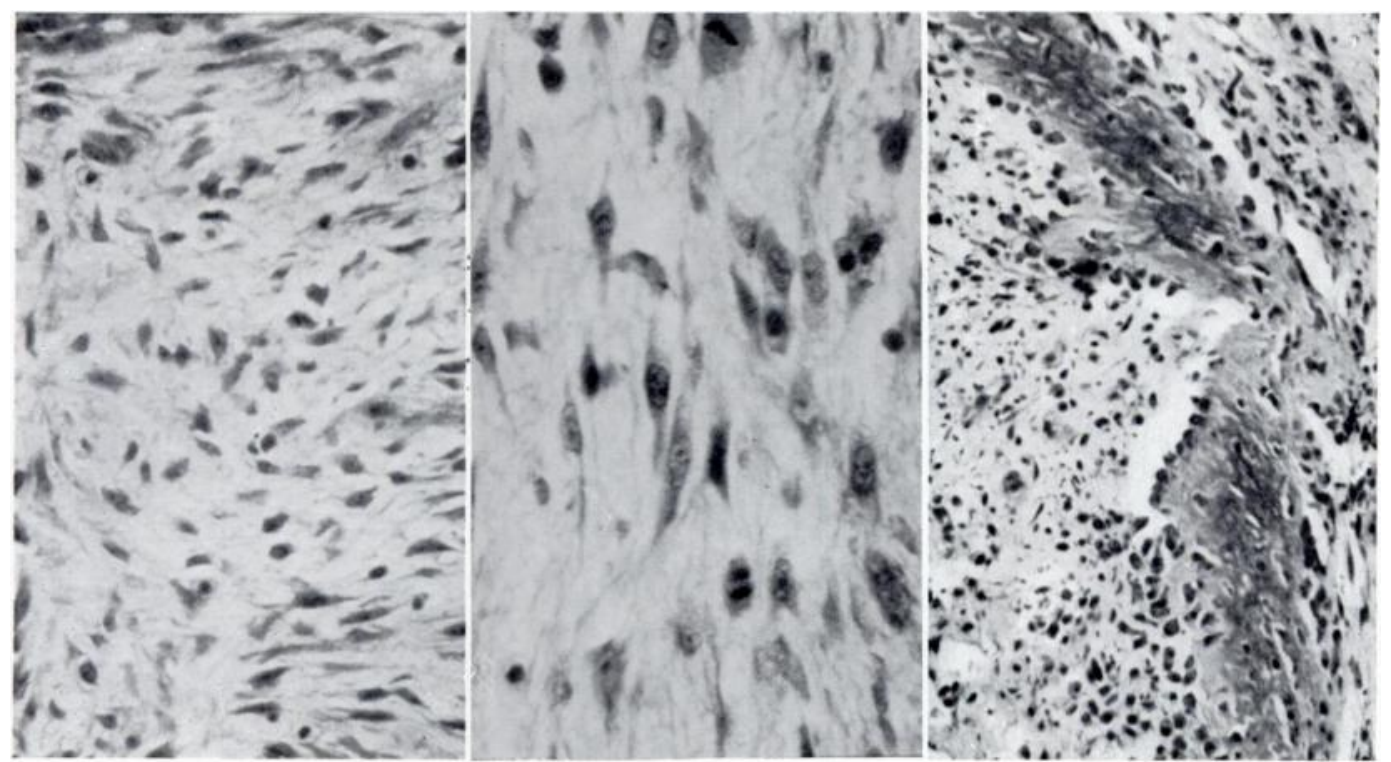

FIG. 7
Fig. 9

Case 1. Figure 7-Photomicrograph of the specimen showing young rapidly proliferating fibroblastic tissue and the remains of muscle fibres. (Haematoxylin and eosin, $\times 195$.) Figure 8 -Higher power view showing stellate and spindle-shaped cells. (Haematoxylin and eosin, $\times 345$.) Figure 9-More advanced changes with osteoid and bone formation. (Haematoxylin and eosin, $\times 135$.)

vOL. 52 B, NO. 2, MAY 1970 
osteoblasts into osteoid tissue and finally into early bone formation (Fig. 9). Myositis ossificans was diagnosed. Confusion arose when another pathologist confidently reported the sections to indicate an osteosarcoma. However, eleven days after admission a further radiograph showed a large calcified mass which confirmed the diagnosis (Figs. 2 and 3 ).

Progress-The limb was supported in a Thomas's splint for one month and then in a weightrelieving caliper. The patient is well four years later with full movements of the hip and knee. Although the mass regressed clinically and radiologically, it has been stationary over the last three years and is not causing symptoms (Figs. 4 and 5).

Case 2-A schoolboy aged eighteen complained fcr two weeks of pain in the buttock, extending down the back of the thigh, this being present when sitting in a chair or when moving the legs. There was no pain or limp when walking. There was no history of injury. He was acutely

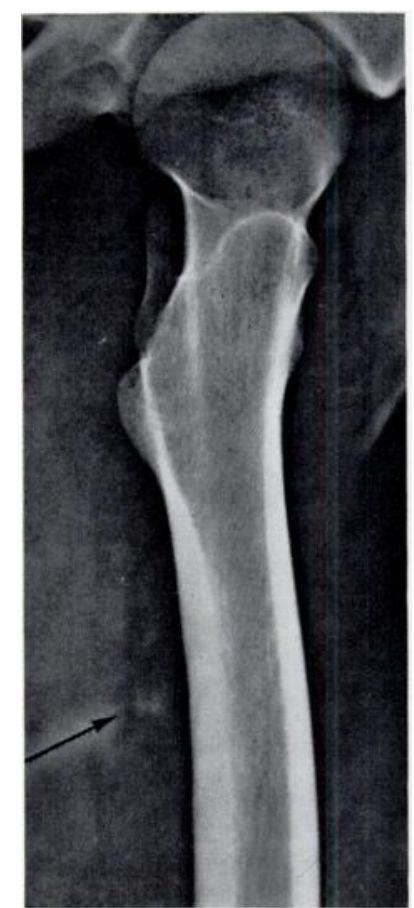

FIG. 10

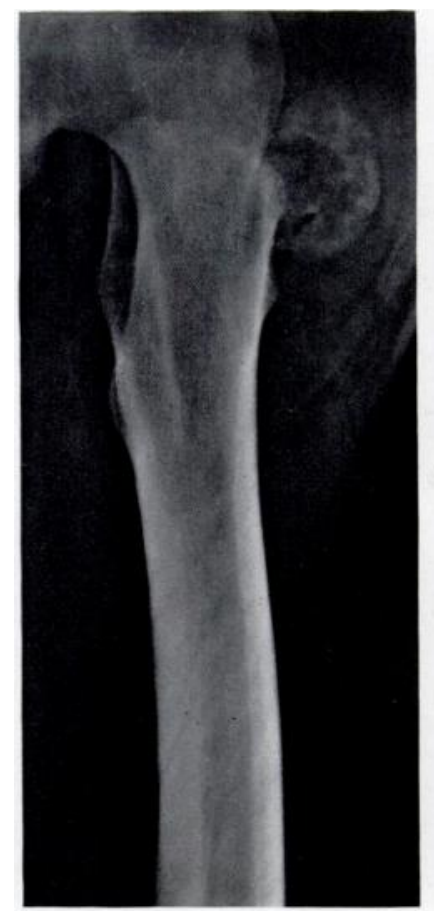

FIG. 11

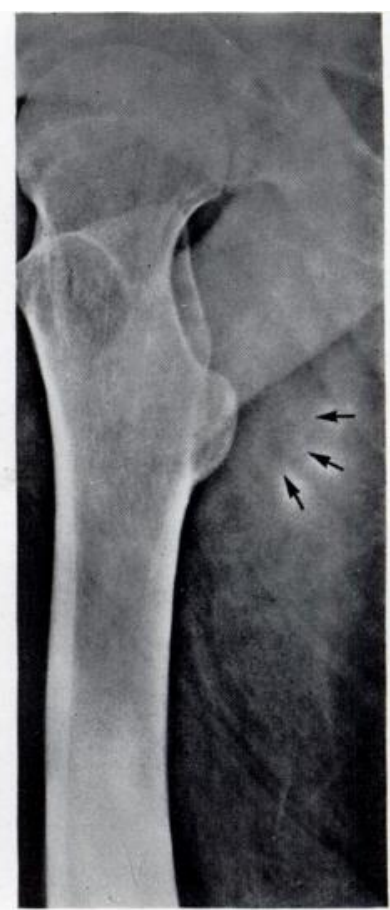

Fig. 12

Figure 10-Case 2. Lateral radiograph of the buttock showing early calcification two weeks after the onset of symptoms. Figure 11-Case 3. Lateral radiograph of the thigh showing a calcified mass in front of the hip joint seven weeks after the onset of symptoms. At this stage there was no tenderness. Figure 12-Case 4. Lateral radiograph of the thigh showing fine calcification in the buttock four weeks after the onset of symptoms.

tender over a small, discrete area in the lower part of the buttock, with some suggestion of fullness. Restriction of full flexion of the hip joint was the only other clinical abnormality. Blood and radiological investigations were normal.

Over the next two weeks he developed increasing pain, limp and a firm, very tender swelling in the buttock. He was otherwise well. A further radiograph suggested a little calcification in the buttock (Fig. 10). Exploration was advised because of increasing pain and rapid growth of the swelling, the differential diagnosis being between myositis ossificans and osteosarcoma.

A hard discrete swelling approximately five centimetres in diameter was found loosely attached to the periosteum involving the tendinous insertion of gluteus maximus muscle. The mass was removed. It consisted of firm fleshy creamy tissue with muscle in one part and calcification at one end. The histological picture was the same as that in Case 1. 
This boy had complete relief of his symptoms. Four years later there was no clinical or radiological evidence of recurrence.

Case 3-A boy aged fifteen gave a four-week history of increasing pain in front of the hip joint. There was no history of injury and he was otherwise well. He had a marked limp with marked increase of lumbar lordosis and a lateral tilt of the lumbar spine, movements of which were however full and painless. There was a flexion and abduction deformity of the hip joint with some wasting of the thigh muscles. There was a tender swelling measuring eight by five centimetres in the anterior aspect of the upper thigh. Blood and radiographic investigations were normal. Myositis ossificans in the upper part of the rectus femoris muscle was diagnosed.

After three weeks' rest he had no pain or limp, no deformity, and full joint movements. The swelling had become firm and non-tender. It was now calcified radiologically (Fig. 11). He avoided strenuous activity for six months by which time the mass was disappearing. Four years later he remains well and there is no clinical or radiological evidence of the mass.

Case 4-A man aged twenty-four presented with a painful swelling in the right buttock for one month. He was not aware of any injury, but on examination there was a firm tender swelling in the buttock approximately five by three centimetres in size. Radiographs revealed an area of fine calcification in the soft tissues of the buttock (Fig. 12). The mass was explored and found to consist of a hard tumour in the gluteus maximus muscle near its musculo-tendinous junction. It was excised completely (Figs. 13 and 14). Histological sections again showed the classical picture of myositis ossificans. Four years later he has complete relief of his symptoms and there has been no recurrence.

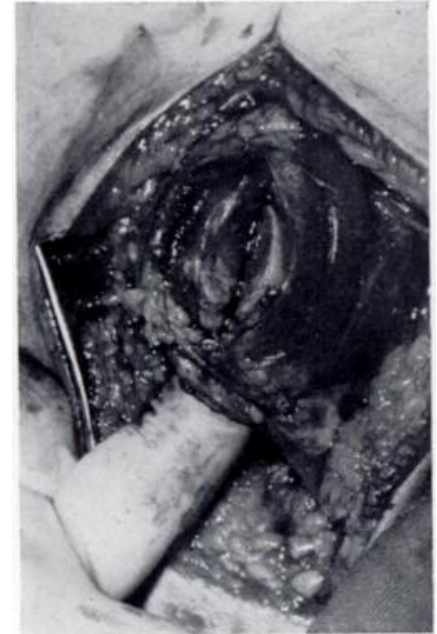

Fig. 13

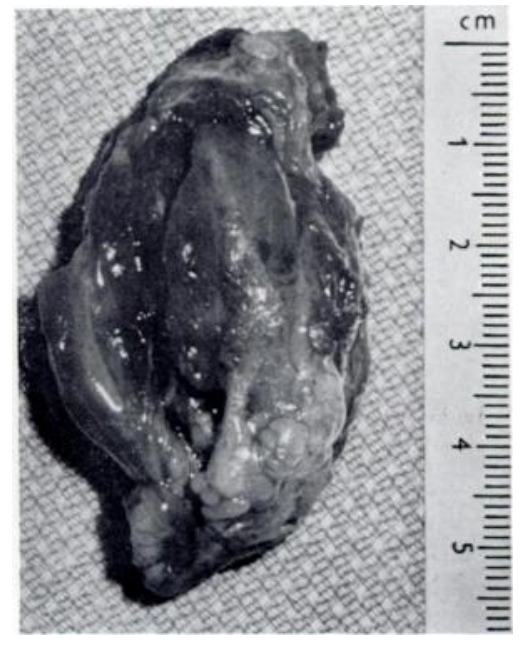

FiG. 14

Case 4. Figure 13-Photograph of the mass in situ at operation. Figure 14The specimen after removal.

\section{DISCUSSION}

Myositis ossificans usually occurs in early adult life, predominantly in healthy, vigorous young men. The cause and mechanism remain unknown. It is possible, but as yet unproved, that the initial change is damage to muscle with both interstitial haemorrhage and muscle necrosis playing an important part. Others consider that it is initiated by an excessive proliferation of fibroblasts while some speculate that the new bone arises by metaplasia of local fibrous tissue. Injury is undoubtedly an important factor but is obviously not the only cause of the condition.

VOL. 52 B, NO. 2, MAY 1970 
Clinical course-As a rule initially there is development of pain and a swelling associated with some limitation of movement of the adjacent joint. The radiograph at this stage is normal. By the end of four weeks the swelling has increased and radiography may show an irregular and distinct shadow parallel to the bone but separated by a light zone. There is no erosion of the shaft of the bone. The swelling then becomes firmer and more discrete while pain disappears and radiography shows a sharply limited mass that becomes denser and more homogeneous. Characteristically, ossification is most pronounced at the periphery of the mass in the early stages. The period of active growth varies from ten weeks to six months and the lesion may become very large, especially when it occurs in the buttock.

Blood chemistry-Most authors have reported that the serum calcium, serum phosphorus and serum alkaline phosphatase estimations have been normal in myositis ossificans. The cases in this series had normal blood chemistry.

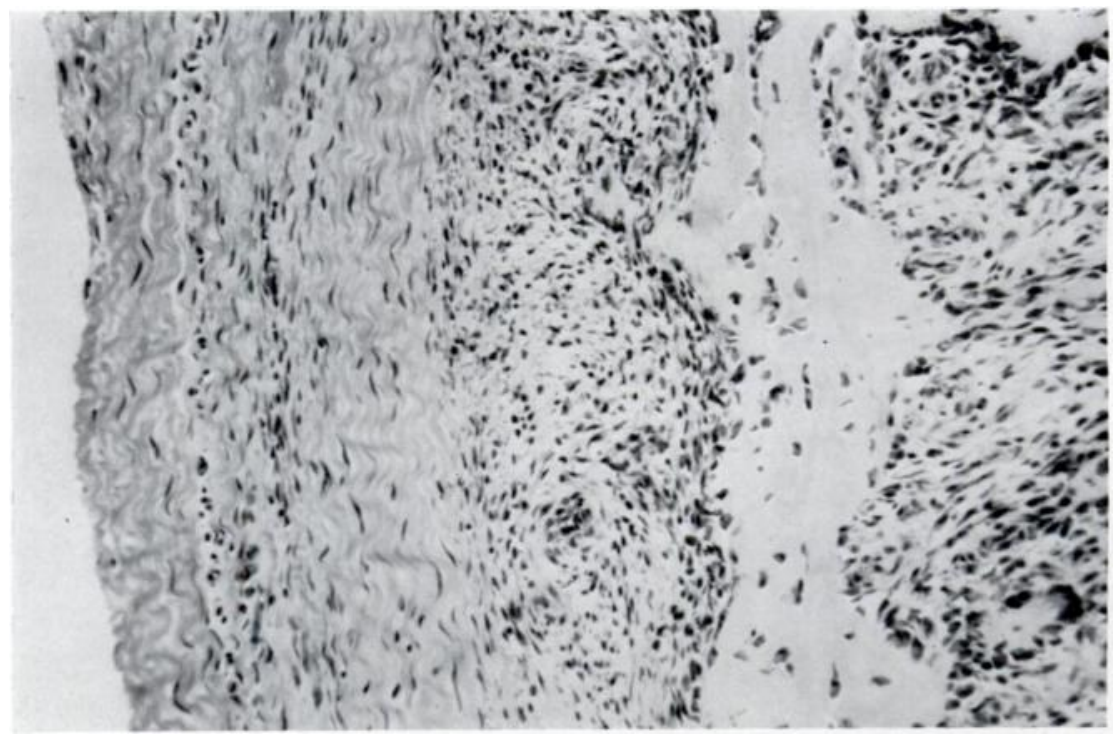

FIG. 15

Case 1-Photomicrograph showing zone formation in myositis ossificans circumscripta. (Haematoxylin and eosin, $\times 110$.)

Microscopic appearance-Ackerman and Spjut (1962) and others have stressed the establishment of "zonal" phenomena in this lesion. The undifferentiated pattern during the early development of the lesion, perhaps in the first ten days, makes histological diagnosis extremely difficult. Varying degrees of differentiation into three zones then occurs and produces the characteristic picture of myositis ossificans and establishes the diagnosis. There is initially a zone of young rapidly proliferating fibroblastic tissue containing many mitotic figures, then a zone of osteoblasts with the formation of osteoid material, and finally further organisation and calcification producing the third zone of well-formed bone covered with a connective tissue capsule. Any surrounding muscle is compressed and does not reveal invasion by this tissue. This zone formation can be seen in Figure 15.

Differential diagnosis-This is not usually difficult except in the early stage when many confusing conditions such as haematoma, callus, muscle tumours, osteomyelitis, periostitis and neoplasms have to be excluded. The most important differential diagnosis is osteosarcoma; the distinguishing features are: 1) Myositis ossificans is situated over the shaft of a bone whilst osteosarcoma is near the end of the bone. 2) In myositis ossificans there is initial rapid increase in the swelling with a tendency then for it to diminish in size. Its uniformly hard consistency, together with the pain which begins early and gradually loses its intensity, is in contrast with 
that found in osteosarcoma. 3) Radiologically the cortex and periosteum are normal in myositis ossificans and the newly formed mass lies parallel to the surface. Stereoscopic views help to reveal an intact cortex, which of course is broken in osteosarcoma. 4) Microscopically, the "zonal" arrangement of osteoid tissue and osseous trabeculae, combined with the lack of true anaplasia in the proliferating cells, affords the pathologist the necessary diagnostic clue to exclude osteosarcoma. For a diagnosis of osteosarcoma active fibroblastic proliferation with the presence of osseous material amongst these cells and not a gradual gradation from one zone to the other is required. The presence of viable muscle cells is important because tumours destroy muscle as they advance.

Fine and Stout (1956) found twelve cases of extraosseous sarcoma complicating myositis ossificans, but Dahlin (1957) questioned the authenticity of such cases.

Treatment-Treatment should be by rest to the affected part with graduated active exercises as pain and swelling subside. When the diagnosis is in doubt and there is no involvement of the cortex, Coley and Higinbotham (1953) considered a delay of two to three weeks justifiable if followed by further radiographs, which would then confirm the presence of an ossifying mass and establish the diagnosis.

Excision is indicated where the lump is unusually large or very painful. Recurrence is stated by some to be common but has not occurred in Cases 2 and 4. Dahlin (1957) stated quite definitely that such recurrences are benign.

The necessity for biopsy or excision of a benign lesion can be evaluated correctly only when the pathologist knows the history, location and duration of the process. Once it is diagnosed, treatment is unnecessary.

Prognosis-An excellent prognosis is to be expected with either conservative treatment or excision of the mass.

\section{SUMMARY AND CONCLUSIONS}

1. Four cases of myositis ossificans circumscripta are presented.

2. It remains an obscure condition but there are characteristic clinical, radiological and microscopical features.

3. While the majority of cases arise as a direct result of injury, these four cases suggest that this is not always so; the diagnosis from osteosarcoma, bone or joint infection may then be difficult.

4. Noble's classification (1924) of myositis ossificans is adequate and should be accepted. Confusion would be avoided if cases such as those presented here were included in the classification suggested.

I wish to thank Mr Wallace Jolly and $\mathrm{Mr}$ Colin Paull for allowing me to present Cases 1 and 4 respectively, and Dr Malcolm Fowler, Pathologist, of the Adelaide Children's Hospital, for valuable guidance in the preparation of this paper. I also thank Mr Ray Boyd, Clinical Photographer of the Adelaide Children's Hospital, for his cooperation.

\section{REFERENCES}

Ackerman, L. V. (1958): Extra-osseous Localized Non-neoplastic Bone and Cartilage Formation (So-called Myositis Ossificans). Journal of Bone and Joint Surgery, 40-A, 279.

Ackerman, L. V., and Spjut, H. J. (1962): Tumours of Bone and Cartilage. United States Armed Forces Institute of Pathology. Atlas of Tumor Pathology. Section 2. Fascicle 4. P. 279. Washington, D.C.: The Armed Forces Institute of Pathology.

Coley, B. L., and Higinbotham, N. L. (1953): Tumours of Bone. London: Cassell and Company Limited.

Dahlin, D. C. (1957): Bone Tumors. Springfield, Illinois: Charles C. Thomas.

Fine, G., and Stout, A. P. (1956): Osteogenic Sarcoma of the Extraskeletal Soft Tissues. Cancer, 9, 1027.

Jefrreys, T. E., and Stiles, P. J. (1966): Pseudomalignant Osseous Tumour of Soft Tissue. Journal of Bone and Joint Surgery, 48-B, 488.

Noble, T. P. (1924): Myositis Ossificans, a Clinical and Radiological Study. Surgery, Gynecology and Obstetrics. 39, 795.

vol. 52 B, NO. 2, MAY 1970 